\title{
Evaluation of Risk Factors Associated with Rotaviral Diarrhoea among Under Five Children in Sylhet Region of Bangladesh
}

\author{
Habib FB ${ }^{1}$, Rahman $\mathrm{MM}^{2}$, Haque $\mathrm{MM}^{3}$, Dey $\mathrm{PR}^{4}$, Das $\mathrm{P}^{5}$, Das $\mathrm{S}^{6}$, Sutradhar $\mathrm{I}^{7}$, Hasan $\mathrm{MN}^{8}$
}

\begin{abstract}
Retrovirus is the major cause of acute severe diarrhea in under five children and contributing 10,000 to 27000 deaths each year in Bangladesh. This cross-sectional study was designed to determine the risk factors associated with Rotaviral among under five children admitted in the Department of Paediatrics, Sylhet MAG Osmani Medical College Hospital, Sylhet and was carried out in the Department of Microbiology during the period from 1st January to 31st December, 2018. Total 184 under five children with acute watery diarrhoea were enrolled in this study by convenient sampling. Stool samples were obtained and assayed for rotavirus antigens by enzyme linked immunosorbent assay (ELISA). Rotaviral antigen was found positive in 86 cases. The Rotavirus infection was found highest in age group of 7 to 12 months (50.56\%) and in male (59.30\%) children. It was found significantly higher in patients from lower socio-economic condition (64.00\%), those
\end{abstract}

1. *Dr. Farjana-Binte-Habib, Lecturer, Department of Microbiology, Shaheed Tajuddin Ahmad Medical College. Gazipur. Email: farjanahabib33 @gmail.com Mobile: 01767846944

2. Dr. Mohammed Mirazur Rahman, Resident [MD Phase B], Pulmonology, BSMMU

3. Prof.Dr. Md. Moynul Haque, Professor \& Head of the Department of Microbiology, Sylhet MAG Osmani Medical College, Sylhet.

4. Prof. Dr. Probhat Ranjan Dey, Professor \& Head of the Department of Paediatrics, Sylhet MAG Osmani Medical College Hospital, Sylhet.

5. Asst. Dr. Premananda Das, Assistant Professor, Department of Microbiology,Sylhet MAG Osmani Medical College, Sylhet.

6. Dr. Shantanu Das, Lecturer, Department of Microbiology, Sylhet MAG Osmani Medical College, Sylhet.

7. Dr. Ipsita Sutradhar, Research fellow, BRAC James P. Grant School of Public Health, BRAC University, Mohakhali, Dhaka- 1212

8. Dr. Md. Nazmul Hasan, Asst. Prof. Department of Internal Medicine, BSMMU

*For correspondence who were from rural area (48.75\%) and children who were not exclusively breastfed (83.87\%). Bottle feeding, lower educational level of mother and overweight of children may serve as predisposing factors of rotavirus disease in these children.

Keywords: Rota virus, watery diarrhoea, ELISA, risk factors, Exclusive Breast Feeding

\section{INTRODUCTION}

Rotavirus is the major cause of acute severe dehydrating diarrhoea in children below five years. ${ }^{1}$ This virus was first described by electron microscopic examination of duodenal biopsies from children with acute gastroenteritis. ${ }^{2}$ Rotavirus is classified into seven groups, A to G. Group A is responsible for more than $90 \%$ of Rotavirus gastroenteritis in infants and young children. ${ }^{1,3}$ Rotavirus is transmitted through the faeco-oral route having low infective dose. ${ }^{4}$

Rotaviral diarrhoea is contributing a significant proportion of morbidity and mortality in under five children. Rotavirus causes approximately 121,000 deaths in developing countries of Africa and South Asia and approximately 215,000 deaths per year in children less than 5 years of age worldwide. ${ }^{5}$

In Bangladesh, Rotavirus is the major cause of under-five diarrhoea and diarrhoeal deaths. ${ }^{6}$ A study conducted by icddr,b in Matlab, Bangladesh from 2006 to 2012 revealed that prevalence of Rotaviraldiarrhoea was $20.3 \%$ among under 5 children. ${ }^{7}$ According to WHO, Rotaviral diarrhoea causes 1000-2700 deaths each year in children $<5$ years of age in Bangladesh. ${ }^{8}$

Several risk factors are responsible for Rotaviral infection in children. The most common risk factors are low birth weight, male gender, 6-24 months age group (due to more exposure to contaminated materials in this age group), children attending daycare, poor food hygiene, playing with toys, bottle-feeding, low literacy status of mother ${ }^{9,10}$. Hospital acquired infection due to Rotavirus also occurs ${ }^{3}$.

Clinical presentation of Rotaviral diarrhoea resembles the same as in diarrhoea due to other etiology. It has no specific anti-viral treatment. Good hygiene reduces the transmission 
of virus. But even in the most hygienic societies, virtually all children experience Rotavi- raldiarrhoea as a result of high infectivity of the virus. Exclusive breast feeding, handwashing and isolation procedures can help to control disease spread.

So, this study was designed to evaluate the risk factors associated with Rotaviral diarrhoea among children less than 5 years.

\section{MATERIALS AND METHODS}

This cross-sectional study was carried out in the department of Microbiology in collaboration with the department of Paediatrics, Sylhet MAG Osmani Medical College Hospital from 1st January 2018 to 31st December 2018. All admitted children under 5 years of age with acute watery diarrhoea were included in this study. They were assessed thoroughly by detail history and physical examination. Those who met the selection criteria were enrolled as study population. Children suffering from chronic diarrhea (diarrhoea for $\geq 14$ days) and bloody diarrhea were excluded. After explaining the purpose of the study, informed written consent was taken from each patient or legal guardian. Data collectionwas done by pre-designed data collection sheet. Prior to the beginning of this study, approval of the research protocol was obtained from the Ethical Review Committee of Sylhet MAG Osmani Medical College, Sylhet.

\section{RESULT}

Distribution of study population according to stool antigen test by ELISA:

Table-I shows the stool antigen positive in $86(46.74 \%)$ and negative in $98(53.26 \%)$ patients.

Table I: Distribution of study population according to stool antigen test by ELISA $(n=184)$

\begin{tabular}{|l|c|c|}
\hline ELISA & Frequency & Percentage \\
\hline Positive & 86 & 46.74 \\
\hline Negative & 98 & 53.26 \\
\hline Total & 184 & 100.0 \\
\hline
\end{tabular}

Distribution of of Rotavirus diarrhoea according to age group:

Table-II shows the prevalence of Rotaviral diarrhoea among 0.6 months age group $11.11 \%$ and $7-12$ months age group children $(50.56 \%)$ followed by $13-24$ months age group children (48.28\%).
Table II: Prevalence of Rotavirus diarrhoea (ELISA $+v e$ ) among under 5 years children according to their age $(n=184)$

\begin{tabular}{|c|c|c|c|c|c|}
\hline \multirow[t]{2}{*}{ Variable } & \multicolumn{2}{|c|}{ ELISA (+ve) } & \multicolumn{2}{|c|}{ ELISA (-ve) } & \multirow{2}{*}{$\begin{array}{c}P \\
\text { value }\end{array}$} \\
\hline & $\mathbf{n}$ & (\%) & $\mathrm{n}$ & $(\%)$ & \\
\hline \multicolumn{6}{|c|}{ Age (months) } \\
\hline $0-6$ & 2 & 11.11 & 16 & 88.89 & $0.004^{*}$ \\
\hline $7-12$ & 50 & 50.56 & 40 & 49.44 & \\
\hline $13-24$ & 28 & 48.28 & 30 & 51.72 & \\
\hline $25-59$ & 6 & 33.33 & 12 & 66.67 & \\
\hline
\end{tabular}

$*$ P value $<0.05$ statistically significant

$\mathrm{X}^{2}$ test was employed to analyze the data

Distribution of Rotavirus diarrhoea according sex of the participants.

Table-III shows the prevalence rate among male children (59.30\%) compared to female children.

Table III: Prevalence of Rotavirus diarrhoea (ELISA $+v e$ ) among under 5 years children according to their gender $(\mathbf{n}=184)$

\begin{tabular}{|l|c|c|c|c|c|}
\hline \multirow{2}{*}{ Variable } & \multicolumn{2}{|c|}{ ELISA (+ve) } & \multicolumn{2}{|c|}{ ELISA (-ve) } & \multirow{2}{*}{ P value } \\
\cline { 2 - 5 } & $\mathrm{n}$ & $(\%)$ & $\mathrm{n}$ & $(\%)$ & \\
\hline Gender & & & & & \\
\hline Male & 51 & 59.30 & 71 & 72.45 & 0.060 \\
Female & 35 & 40.70 & 27 & 27.55 & \\
\hline
\end{tabular}

${ }^{*} P$ value $<0.05$ statistically significant

$\mathrm{X} 2$ test was employed to analyze the data

Distribution of Rotavirus diarrhoea according to socio-economic status.

Table-IV shows the prevalence rate among children belong to low socio-economic status $(64.00 \%)$ than the children from middle socio-economic status $(26.19 \%)$.

Table IV: Prevalence of Rotavirus diarrhoea (ELISA $+v e$ ) among under 5 years children according to their socio-economic status $(\mathrm{n}=184)$

\begin{tabular}{|c|c|c|c|c|c|}
\hline Variable & \multicolumn{2}{|c|}{ ELISA (+ve) } & \multicolumn{2}{|c|}{ ELISA (-ve) } & $P$ value \\
\hline & $\mathrm{n}$ & $(\%)$ & $\mathrm{n}$ & $(\%)$ & \\
\hline \multicolumn{3}{|c|}{ Socioeconomic status } & & & \\
\hline Middle & 22 & 26.19 & 62 & 73.81 & $0.001^{*}$ \\
\hline Lower & 64 & 64.00 & 36 & 36.00 & \\
\hline
\end{tabular}

${ }^{*} P$ value $<0.05$ statistically significant

$\mathrm{X}^{2}$ test was employed to analyze the data 
Distribution of Rotavirus diarrhoea according to residence of the participants.

Table $\mathrm{V}$ shows the prevalence rate among children from rural residence (48.75\%) compared to urban counterpart.

Table V: Prevalence of Rotavirus diarrhoea (ELISA + ve) among under 5 years children according to their residence $(n=184)$

\begin{tabular}{|l|c|c|c|c|c|}
\hline \multirow{2}{*}{ Variable } & \multicolumn{2}{|c|}{ ELISA (+ve) } & \multicolumn{2}{|c|}{ ELISA (-ve) } & \multirow{2}{*}{ P value } \\
\cline { 2 - 5 } & $\mathrm{n}$ & $(\%)$ & $\mathrm{n}$ & $(\%)$ & \\
\hline Residence & & & & & \\
\hline Urban & 8 & 33.33 & 16 & 66.67 & 0.158 \\
\hline Rural & 78 & 48.75 & 82 & 51.25 & \\
\hline
\end{tabular}

${ }^{*} P$ value $<0.05$ statistically significant

$\mathrm{X}^{2}$ test was employed to analyze the data

\section{Distribution of Rotavirus diarrhoea according to breast feeding.}

Table-VI shows the prevalence rate of Rotavirus diarrhoea among children who has no give any history of exclusive breast feeding $(83.87 \%)$ and this association was statistically significant $(\mathrm{p}=0.01)$.

Table Vl: Prevalence of Rotavirus diarrhoea (ELISA $+v e$ ) among under 5 years children according to their breast feeding $(\mathbf{n}=184)$

\begin{tabular}{|c|c|c|c|c|c|}
\hline \multirow[t]{2}{*}{ Variable } & \multicolumn{2}{|c|}{ ELISA (+ve) } & \multicolumn{2}{|c|}{ ELISA (-ve) } & \multirow{2}{*}{$\begin{array}{c}\mathrm{P} \\
\text { value }\end{array}$} \\
\hline & $\mathrm{n}$ & $(\%)$ & $\mathrm{n}$ & $(\%)$ & \\
\hline \multicolumn{6}{|l|}{ Breast feeding } \\
\hline History of EBF & 32 & 26.23 & 90 & 73.77 & $0.000^{*}$ \\
\hline No history of EBF & 52 & 83.87 & 10 & 16.13 & \\
\hline
\end{tabular}

${ }^{*} P$ value $<0.05$ statistically significant

$\mathrm{X}^{2}$ test was employed to analyze the data

Distribution of Rotavirus diarrhoea according to bottle feeding.

Table-VII shows the prevalence rate of Rotavirus diarrhoea among children who were bottle-fed $(73.53 \%)$.
Table Vl1: Prevalence of Rotavirus diarrhoea (ELISA $+v e$ ) among under 5 years children according to bottole feeding ( $n=184)$

\begin{tabular}{|l|c|c|c|c|c|}
\hline \multirow{2}{*}{ Variable } & \multicolumn{2}{|c|}{ ELSA (+ve) } & \multicolumn{2}{|c|}{ ELISA (-ve) } & P value \\
\cline { 2 - 5 } & $\mathrm{n}$ & $(\%)$ & $\mathrm{n}$ & $(\%)$ & \\
\hline Bottle feeding & & & & & \\
\hline Yes & 50 & 73.53 & 18 & 26.47 & $0.05^{*}$ \\
\hline No & 36 & 31.03 & 80 & 68.97 & \\
\hline
\end{tabular}

${ }^{*} P$ value $<0.05$ statistically significant

$\mathrm{X}^{2}$ test was employed to analyze the data

Distribution of Rotavirus diarrhoea according to mother's education of the participants.

Table-VIII shows the acute watery diarrhoea prevalent among the children of uneducated or less educated mothers (illiterate-87.50\%, primary complete- $83.87 \%$ ) than their counterparts whose mother had better education (secondary complete-15.62\%, higher secondary-33.33\%).

Table VIll: Prevalence of Rotavirus diarrhoea (ELISA $+v e$ ) among under 5 years children according to mother's education of the participants $(n=184)$

\begin{tabular}{|c|c|c|c|c|c|}
\hline \multirow[t]{2}{*}{ Variable } & \multicolumn{2}{|c|}{ ELISA (+ve) } & \multicolumn{2}{|c|}{ ELISA (-ve) } & \multirow{2}{*}{$\begin{array}{c}\mathrm{P} \\
\text { value }\end{array}$} \\
\hline & $\mathrm{n}$ & $(\%)$ & $\mathrm{n}$ & $(\%)$ & \\
\hline \multicolumn{5}{|l|}{ Mother's education } & \multirow{6}{*}{$0.01^{*}$} \\
\hline Illiterate & 7 & 87.50 & 1 & 12.50 & \\
\hline Primary complete & 52 & 83.87 & 10 & 16.13 & \\
\hline Secondary incomplete & 20 & 43.48 & 26 & 56.52 & \\
\hline Secondary complete & 10 & 15.62 & 54 & 84.38 & \\
\hline Higher secondary & 4 & 33.33 & 8 & 66.67 & \\
\hline
\end{tabular}

${ }^{*} P$ value $<0.05$ statistically significant

$\mathrm{X}^{2}$ test was employed to analyze the data

Distribution of Rotavirus diarrhoea according to weight for age of the participants.

Table-IX shows the overweight children (60.00\%) suffered from Rotaviral diarrhoea while compared to normal weight (35.29\%) or moderately underweight children (46.97\%). 
Table 1X: Prevalence of Rotavirus diarrhoea (ELISA $+v e$ ) among under 5 years children according to their weight for age $(n=184)$

\begin{tabular}{|l|c|c|c|c|c|}
\hline \multirow{2}{*}{ Variable } & \multicolumn{2}{|c|}{ ELISA (+ve) } & \multicolumn{2}{|c|}{ ELISA (-ve) } & \multirow{2}{*}{$\begin{array}{c}\text { P } \\
\text { value }\end{array}$} \\
\cline { 2 - 5 } & $\mathrm{n}$ & $(\%)$ & $\mathrm{n}$ & $(\%)$ & \\
\hline Weight for age & & & & & \\
\hline Severely underweight & 3 & 34.50 & 5 & 65.50 & $0.459^{*}$ \\
\hline Moderately underweight & 62 & 46.97 & 70 & 53.03 & Normal \\
\hline weight & 12 & 35.29 & 22 & 64.71 & \\
\hline Overweight & 6 & 60.00 & 4 & 40.00 & \\
\hline
\end{tabular}

${ }^{*} P$ value $<0.05$ statistically significant

$\mathrm{X}^{2}$ test was employed to analyze the data

\section{DISCUSSION}

In the present study, highest prevalence of Rotaviral diarrhoea was found in children of 7-12 months of age group (51.89\%). This is in agreement with the results of a study done in Nigeria where most of the infected children (42\%) were found between 7 to 12 months of age group ${ }^{10}$. It appeared that infants below 6 months of age are initially protected to some extent against Rotavirus diarrhoea due to presence of maternal antibodies. After 6 months when maternal antibody decreases, rate of infection increases. ${ }^{11}$ In this age group (7-12 months), children start crawling and develop tendency to put almost everything into mouth which can increases the chance of infection. ${ }^{12}$ Another reason can be that the weaning is started at this age. So, there is chance of contamination of food during preparation if hand washing and food hygiene is not maintained properly. Frequency of Rotaviral infection was less in higher age group due to acquisition of antibody by natural infection. ${ }^{13}$

In this study, highest prevalence of Rotaviraldiarrhoea was found among male gender (61.90\%). This result is in agreement with previous Bangladeshi studies, where it was reported that around $58 \%{ }^{14}$ and $54 \%{ }^{15}$ children were male. Similar result was found from an Indian study done by Agarwal and co-workers where $62.7 \%$ male children were affected ${ }^{16}$ and an Ethiopian study done by Sisey et al. who found that Rotaviral affected male was $59.6 \%{ }^{17}$ which is comparable to our study. This male predominance is not clearly understood. It can be explained by social reason that the tendency of parents to prioritize their male children than female in seeking any kind of health care. This finding can also be explained by more resistance to infection in females due to $\mathrm{XX}$ chromosome. ${ }^{18}$ However, this difference was not found statistically significant.
This study revealed that the Rotaviraldiarrhoea was higher among children who belong to lower socio-economic status $(62.00 \%)$ than the children from middle socio-economic status (26.19\%). This finding is in resemblance with the finding of an Indian studies done in Amritsar ${ }^{18}$. This can be explained by unhygienic behaviour, not having or using sanitary latrine and less ability to avail standard health care facility. As Rotaviral infection is highly communicable, overcrowding living condition can also explain this finding. As the treatment in private hospital is expensive, the poor usually come to the government hospital. It might be one of the reasons of more availability of poor patients in our study. So, this picture may not represent the actual situation.

This study also found that, prevalence of Rotavirus diarrhoea was higher among children who were from rural area $(47.50 \%)$ compared to their urban counterparts (33.33\%). This finding is in harmony with a previous finding of a study done in Ethiopia where 96.5\% positive cases were from rural area. ${ }^{17}$ It can be explained by lack of health education, improper sanitation or lower availability of health care facility in rural areas comparing to urban areas.

Present study found that, prevalence of Rotavirus diarrhoea was higher among children who were not exclusively breastfed $(83.87 \%)$ and this association was found statistically significant. This finding is found similar with a Bangladeshi study done by Ferdous et al. ${ }^{19}$ and another study done in Iraq by Azeez and Alsakee ${ }^{20}$ found a higher incidence of Rotavirus diarrhoea in infants those were not exclusively breastfed. This finding can be explained by the protective immunological effects of breastmilk in infants and young children. IgA and IgG from colostrum and breast milk protects children from Rotavirus infection and also reduces the severity of Rotavirus diarrhoea. Lactadherin and oligosaccharide of breast milk prevent Rotavirus from binding with the receptor of small intestine. $^{21,22}$ Previous studies conducted among under 5 years old children in other countries like India and Nepal also reported that incidence of Rotaviraldiarrhoea increases after 6 months of age. They suggested that exclusive breast feeding is the main reason of lower incidence of Rotaviraldiarrhoea during first 6 months of life. ${ }^{18,23}$

This study found that, prevalence of Rotavirus diarrhoea was higher among children who were bottle-fed (76.47\%) and this association was found statistically significant. Dhiman showed that bottle feeding increases chance of Rotaviral infection (52.38\%). ${ }^{18}$ John, Devgan and Mitra ${ }^{24}$ 
from India and Azeez and Alsakee ${ }^{20}$ from Iraq reported the same. One reason is that, formula milk and other foods lack protective nutrients like IgA, IgG, lactadherin and glycans of breast milk. So, formula milk or other foods cannot provide protection against Rotaviral infection. On the other hand, feeding bottles can easily be contaminated and use of these unhygienic bottles may be the reason behind the higher rate of infection among bottle-fed children.

In the present study, $87.50 \%$ affected children had illiterate mother. This correlates with a previous study done by Sisey et al. who found that $54.4 \%{ }^{17}$ illiterate mother had Rotavirus infected children. This can be explained by lack of maintenance of hygiene. Knowledge gap can also play a significant role for increased prevalence of Rotavirus diarrhoea in the children of less educated mother.

It was found from present study that prevalence of Rotavirus induced diarrhoea was higher $(60.00 \%)$ among overweight children. This finding is in accordance with a previous Bangladeshi study, where it was reported that $55.56 \%{ }^{25}$ of Rotavirus diarrhoea took place among children who were overweight. Ferdous et al. in 2013 also found that Rotavirus infection was more common in well-nourished cases. ${ }^{19}$ A study was done in Mirpur, Dhaka by icddr,b and the most important finding they reported that better nutritional status was strongly associated with a higher risk of Rotavirus diarrhea in the first 3 years of life. ${ }^{15}$ It is evident from previous studies that well-nourished children suffer from Rotaviraldiarrhoea more frequently because of the presence of receptors for Rotavirus in healthy lining epithelium of their intestinal mucosa. But these receptors are absent in the intestinal mucosa of malnourished children due to some pathological changes ${ }^{26,27,28}$. however, the difference was not statistically significant.

\section{CONCLUSIONS}

The overall findings of this study showed that rotavirus is one of the major causes of acute watery diarrhoea in children below five years. Rotavirus infection was found prevalent in children of 7-12 months old with males more susceptible to Rotavirus infection than females. possible risk factors of rotaviral diarroea include lower socioeconomic condition, children from rural area, who were not exclusively breastfed, bottle feeding, lower educational level of mother and overweight of children. Possible other risk factors may be playing with other children, distance of water sources from toilet, attending of day care centers, and playing with toys or consumption of food that do not require cooking. The strategies for rotavirus control include identifying the target population for rotavirus, educating parents and also to know that rotavirus infection in children is unavoidable and should be looked out for. However, the significant higher prevalence in children with lower age and low provision of breast feeding emphasizes the need to pay attention as an important factor of rotavirus diarrhoea. It is particularly important in Bangladesh, where diarrhoea is still contributing a significant proportion of mortality and morbidity in under five children.

\section{LIMITATIONS}

1. The study was conducted in a single center which may not represent the overall disease burden in different other hospitals and geographical locations of the country.

2. Sample size was small.

3. This study did not include outdoor patient. Therefore, study population not representive the community people.

4. Genotyping was not done.

\section{REFERENCES}

1. Pang X and Hodinka RL. In Gastroenteritis Viruses. Manual of clinical microbiology. Jorgensen JH and Pfaller MA (eds). 11th Ed, Washington, DC: ASM press. 2015: 1617-32.

2. Bishop RF, Davidson GP, Holmes IH and Ruck BJ. Virus particles in epithelial cells of duodenal mucosa from children with acute non-bacterial gastroenteritis. THE LANCET. 1973; 302 (7841): 1281-83.

3. Estes MK and Greenberg HB. In Rotaviruses. Fields Virology. Knipe DM and Howley PM (eds). 6th ed, Philadelphia: Lippincott Williams \& Wilkins. 2013; 1347-1401.

4. Miller S. In Virology. Jawetz, Melnick\&Adelberg's Medical Microbiology. Carroll KC, Morse SA, Meitzner TA and Miller S (eds). 27th Ed, New York: McGraw-Hill. 2016; 532-36.

5. Tate JE, Burton AH, Boschi PC and Parashar UD. Global, regional and national estimates of rotavirus mortality in children $<5$ years of age, 2000-2013. Clin Infect Dis. 2016; 62 (2): 96-105. 
6. UNICEF. Committing to Child Survival: A Promise Renewed. Progress Report 2015. New York, 2015: 8-25.

7. Afrad MH, Hassan Z, Farjana S, et al. Changing profile of rotavirus genotypes in Bangladesh, 2006-2012. BMC Infect dis. 2013; 13 (320): 1-7.

8. World Health Organozation (2013): Rotavirus deaths by country 2000-2013. web page at www.who.int/ immunization/monitoring_surveillance/rotavirus [accessed on 12/08/2018].

9. Bernstein DI. "Rotavirus overview". Pediatr Infect Dis J. 2009; 28 (3): 50-53.

10. Junaid SA, Umeh C, Olabode AO and Banda JM. Incidence of rotavirus infection in children with gastroenteritis attending Jos university teaching hospital, Nigeria. Virol J. 2011; 8 (233): 1-8.

11. Majumder N, Barbhuiya NI, Majumder T and Datta SS. Prevelence of Rotaviral infection among children admitted with acute diarrhea in a tertiary care hospital of Tripura. Int J Sci Res. 2018; 7 (3): 105-7.

12. Ahmed S, Kabir ARM, Rahman A, et al. Severity of Rotavirus diarrhea in children: One Year Experience in a Children Hospital in Bangladesh. Iran J Pediatr. 2009; 19 (2): 108-116.

13. Junaid SA, Umeh C, Olabode AO and Banda JM. Incidence of rotavirus infection in children with gastroenteritis attending Jos university teaching hospital, Nigeria. Virol J. 2011; 8 (233): 1-8.

14. Roy S, Shamsuzzaman SM and Mamun KZ. Rapid detection of Rotavirus antigen in stool sample of acute diarrheic children. Ban J Med Microbiol. 2012; 6 (1): 11-13.

15. Verkerke H, Sobuz S, Ma JZ, et al. Malnutrition Is Associated with Protection from Rotavirus Diarrhea: Evidence from a Longitudinal Birth Cohort Study in Bangladesh. J Clin Microbiol. 2016; 54 (10): 2568-74.

16. Agarwal JK, Garg SP, Dayachand and Agarwal D. Comparative Analysis of Enzyme-Linked Immunosorbent Assay and Rapid Card Test for Diagnosis of Rotavirus Antigen in Acute Diarrhea Below Five Years Children. Int J CurrMicrobiol Applied Sci. 2016; 5 (7): 289-94.

17. Sisay MM, Gedefa SM, Zeleke AJ and Solleny GA. Risk Factors of Rotavirus Outbreak Among Children in Kurmuk District, BenishangulGumuz Regional State, Ethiopia. JOJ Case Stud. 2018; 8 (1): 1-6.
18. Dhiman S, Devi B, Singh K, et al. Comparison of Enzyme-Linked Immunosorbent Assay and Immunochromatography for Rotavirus Detection in Children Below Five Years with Acute Gastroenteritis. J Clin Diagn Res. 2015; 9 (9): 6-9.

19. Ferdous F, Das SK, Ahmed S, et al. Severity of Diarrhea and Malnutrition among Under Five-Year-Old Children in Rural Bangladesh. Am J Trop Med Hyg. 2013; 89 (2): 223-28.

20. Azeez SS and Alsakee HM. Cryptosporidium spp. and rotavirus gastroenteritis and change of incidence after rotavirus vaccination among children in Raparin Pediatrics Hospital, Erbil, Iraq. Med J Indones. 2017; 26 (3): 190-97.

21. Morrow AL, Ruiz-Palacios GM, Jiang $\mathrm{X}$, et al. Human-milk glycans that inhibit pathogen binding protect breast-feeding infants against infectious diarrhea. J Nutr. 2005; 135 (5): 1304-07.

22. Newburg DS, Peterson JA, Ruiz-Palacios GM, et al. Role of human-milk lacadherin in protection against symptomatic rotavirus infection. THE LANCET. 1998; 351 (9110): 1160-164.

23. Dhital S, Sherchand JB, Pokhrel BM, et al. Molecular epidemiology of Rotavirus causing diarrhea among children less than five years of age visiting national level children hospitals, Nepal. BMC Pediatr. 2017; 17 (101): 1-7.

24.John BM, Devgan A and Mitra B. Prevalence of rotavirus infection in children below two years presenting with diarrhea. Med $\mathrm{j}$ armed forces india. 2014. 70 (2): 116-19.

25. Sarker MHR, Das SK, Ahmed S, et al. Changing Characteristics of Rotavirus Diarrhea in Children Younger than Five Years in Urban Bangladesh. PLOS ONE. 2014; 9 (8): 1-6.

26. Dewan N, Faruque AS and Fuchs GS. Nutritional status and diarrhoeal pathogen in hospitalized children in Bangladesh. ActaPaediatr. 1998; 87 (6): 627-30.

27. Rodriguez L, Cervantes E and Ortiz R. Malnutrition and Gastrointestinal and Respiratory Infections in Children: A Public Health Problem. Int J Environ Res. Public Health. 2011; 8 (4): 1174-1205.

28. Korpe PS and Petri WA. Environmental Enteropathy: Critical implications of a poorly understood condition. Trends Mol Med. 2012; 18 (6): 328-36. 